\title{
Androgen deprivation therapy as backbone therapy in the management of prostate cancer
}

This article was published in the following Dove Press journal:

OncoTargets and Therapy

29 November 2016

Number of times this article has been viewed

\author{
Axel S Merseburger' \\ Antonio Alcaraz ${ }^{2}$ \\ Christoph A von $\mathrm{Klot}^{3}$ \\ 'Department of Urology, University \\ Hospital Schleswig-Holstein, Campus \\ Lübeck, Germany; ${ }^{2}$ Department of \\ Urology, Hospital Clínic, Barcelona, \\ Spain; ${ }^{3}$ Department of Urology and \\ Urologic Oncology, Hannover Medical \\ School, Hannover, Germany
}

\begin{abstract}
Androgen deprivation therapy (ADT) is well established as a backbone therapy for metastatic prostate cancer ( $\mathrm{mPCa}$ ), and both European and American guidelines emphasize the importance of maintaining ADT after progression to metastatic castration-resistant prostate cancer (CRPC). However, the use of ADT varies widely in clinical practice despite these recommendations. Both research and development of increasingly precise assay technologies have improved our understanding of androgen production and signaling, and the recent data have suggested that a new serum testosterone cutoff value of $<0.7 \mathrm{nmol} / \mathrm{L}$ should be employed. Most clinical trials to date have used the historical $1.7 \mathrm{nmol} / \mathrm{L}$ cutoff, but the $<0.7 \mathrm{nmol} / \mathrm{L}$ cutoff has been associated with improved patient outcomes. Combining agents with different mechanisms of action to achieve intense androgen blockade may improve survival both before and after progression to CRPC. Data suggest that this intensive approach to androgen deprivation could delay the transition to CPRC and hence improve survival dramatically. Various combinations of backbone ADT with chemotherapy or radiotherapy are under investigation. Administration of ADT is established in patients with intermediate or high-risk localized prostate cancer $(\mathrm{PCa})$ receiving radiotherapy with curative intent. This article reviews the current and potential role of ADT as backbone therapy in both hormone-sensitive PCa and CRPC with a focus on $\mathrm{mPCa}$.
\end{abstract}

Keywords: prostate cancer, androgen deprivation therapy, ADT, chemotherapy, radiotherapy, treatment guidelines

\section{Introduction}

The androgen sensitivity of prostate cancer (PCa) is well established, ${ }^{1}$ and androgen deprivation therapy (ADT) has become a cornerstone of treatment, with the potential to halt, or at least slow, the disease progression. ${ }^{2}$ Surgical castration remains the gold standard for ADT, but its effects are permanent, continuous and irreversible. ${ }^{3}$ Nonsurgical treatments have become a more popular choice for ADT, because they allow intermittent therapy and have a lower psychological impact than surgical castration. The National Comprehensive Cancer Network (NCCN) now states that medical castration is as effective as bilateral orchiectomy. ${ }^{4}$

ADT can delay metastatic $\mathrm{PCa}(\mathrm{mPCa})$ progression for around 2 years on average, but most patients will eventually develop castration-resistant PCa (CRPC). ${ }^{5} \mathrm{PCa}$ growth remains dependent on androgen receptor (AR) signaling, even after the development of CRPC, highlighting the need to maintain ADT. ${ }^{6}$

This review outlines the importance of ADT as backbone therapy in CRPC and considers its continued use with existing and new treatment modalities in CRPC. 


\section{Treatment guidelines}

There is a clear consensus on the role of ADT, among current treatment guidelines published by the European Association of Urology, the American Urological Association and the NCCN. ${ }^{3,7-9}$ ADT is recommended in addition to radiotherapy (intermediate and high-risk disease) and for selected patients with biochemical failure (defined as rising prostate-specific antigen [PSA] values). ${ }^{3,6-8}$ Guidelines agree that ADT is the gold standard treatment for $\mathrm{mPCa}$ and that hormone therapy should remain a backbone of treatment following the transition from castration-sensitive disease to CRPC. ${ }^{3,6-8}$

\section{Adherence to guidelines}

Despite consistent guidance to maintain backbone ADT in CRPC, there is a wide variation in actual clinical practice (Figure 1). ${ }^{5}$ Cross-sectional survey data from 3,477 patients with CRPC in five countries (France, Germany, Italy, Spain and the UK) revealed that between $19 \%$ and $45 \%$ (in the UK and Italy, respectively) of patients received chemotherapy alone with no ADT (Figure 1). The reasons for this divergence between guidelines and clinical practice are unclear, and this study reported no consistent link between years of practice and likelihood of continuing ADT in CRPC. ${ }^{5}$ However, this apparent tendency for some clinicians to overlook the need for continued ADT may expose patients to unnecessary risk.

\section{Defining medical castration with ADT}

In defining ADT, regulatory authorities recommend the historical castration cutoff value of $<1.7 \mathrm{nmol} / \mathrm{L}(<50 \mathrm{ng} / \mathrm{dL})$ testosterone, based on early tests that could only detect

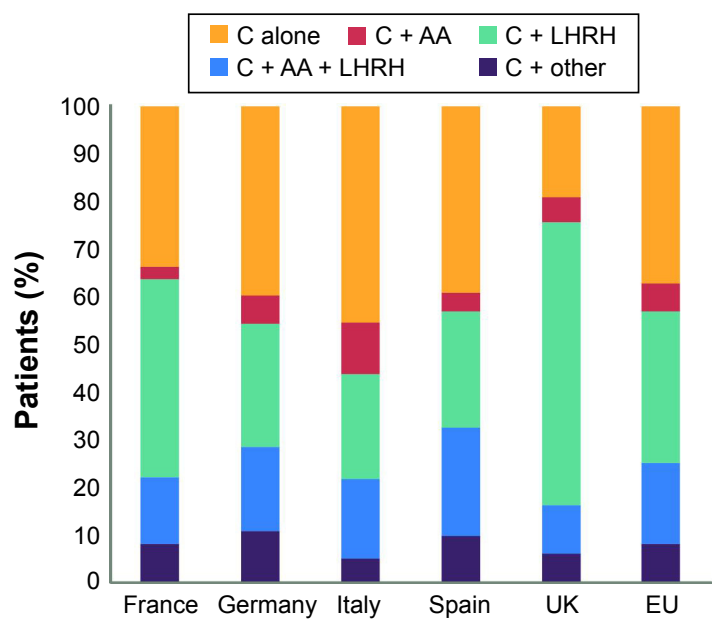

Figure I Treatment patterns across Europe for patients with mCRPC receiving their first chemotherapy regimen.

Note: Reproduced from Sternberg CN, Baskin-Bey ES, Watson M, Worsfold A, Rider A, Tombal B. Treatment patterns and characteristics of European patients with castration-resistant prostate cancer. BMC Urol. 2013;13:58. () Sternberg et al; licensee BioMed Central Ltd. 2013. ${ }^{5}$

Abbreviations: AA, antiandrogen; C, chemotherapy; LHRH, luteinizing hormonereleasing hormone; $\mathrm{mCRPC}$, metastatic castration-resistant prostate cancer. testosterone above this level. However, modern assays, with improved sensitivity, have revealed that the mean testosterone level following bilateral orchiectomy is $0.5 \mathrm{nmol} / \mathrm{L}$ $(15 \mathrm{ng} / \mathrm{dL})$, and a lower cutoff at $<0.7 \mathrm{nmol} / \mathrm{L}$ testosterone may be beneficial. ${ }^{10} \mathrm{~A}$ 6-month retrospective study of 73 men with non-mPCa found that any recorded testosterone peak above $1.1 \mathrm{nmol} / \mathrm{L}(32 \mathrm{ng} / \mathrm{dL}$ ) was associated with significantly impaired survival free of androgen independent progression (88 months [95\% CI, 55-121] versus 137 months [95\% CI, 104-170], respectively; $P<0.03) .{ }^{11}$ In addition, rising PSA levels are commonly used to diagnose CRPC in the clinic, with a minority of oncologists or urologists citing testosterone levels as an additional marker, according to a European survey. ${ }^{5}$ Clinical trials have continued to use the $<1.7 \mathrm{nmol} / \mathrm{L}$ testosterone cutoff, although some studies are starting to explore lower cutoff values. ${ }^{12}$ A recent trial found that gonadotropin-releasing hormone agonist therapy was associated with a $90.0 \%$ probability of maintaining serum testosterone levels of $<0.7 \mathrm{nmol} / \mathrm{L}$ up to 26 weeks, compared with a $96.0 \%$ probability of testosterone levels of $<1.7 \mathrm{nmol} / \mathrm{L}$ ( $95 \%$ CI, 85.0-95.0 and 92.0-99.0, respectively). ${ }^{12}$

Data from 626 patients with PCa with baseline serum testosterone levels above $5.0 \mathrm{nmol} / \mathrm{L}$, more than 12 months after completing definitive radiotherapy in the PR-7 trial, have shown that testosterone values below $0.7 \mathrm{nmol} / \mathrm{L}$ are associated with delayed progression to CRPC and cancer-related death, compared with values above $0.7 \mathrm{nmol} / \mathrm{L} .{ }^{13}$ Patients whose testosterone values reached a nadir below $0.7 \mathrm{nmol} / \mathrm{L}$ had a median time to CRPC of 10 years, versus 7.21 years and 3.62 years with testosterone nadirs between $0.7 \mathrm{nmol} / \mathrm{L}$ and $1.7 \mathrm{nmol} / \mathrm{L}$, and $>1.7 \mathrm{nmol} / \mathrm{L}$, respectively (hazard ratio [HR], 1.62 and $1.90 ; P \leq 0.015) .{ }^{13}$ Median and maximum testosterone levels below $0.7 \mathrm{nmol} / \mathrm{L}$ were also associated with significantly longer times to CRPC, compared with testosterone levels between $0.7 \mathrm{nmol} / \mathrm{L}$ and $1.7 \mathrm{nmol} / \mathrm{L}$, and $>1.7 \mathrm{nmol} / \mathrm{L} .^{13}$ Similarly, patients with minimum or maximum testosterone levels of $>1.7 \mathrm{nmol} / \mathrm{L}$ had significantly shorter times to death due to PCa than patients with minimum or maximum testosterone values of $<0.7 \mathrm{nmol} / \mathrm{L}$ (HR, 2.93 and 2.08 for nadir and maximum value comparisons, respectively; $P=0.02) .{ }^{13}$

This link between very low testosterone levels and improved outcomes corresponds to the observation that lower PSA levels predict longer survival, even to the point of any detectable PSA being linked to worsened outcomes. ${ }^{14}$

\section{Optimizing treatment regimens in hormone-sensitive PCa}

The optimal timing of ADT, whether as monotherapy or in combination with other agents, remains a subject of 
Table I Completed studies with ADT as backbone therapy in PCa

\begin{tabular}{|c|c|c|c|c|}
\hline Study no/name & Phase & $\begin{array}{l}\text { No of } \\
\text { patients }\end{array}$ & Patient population & Design \\
\hline NCT00309985 (CHAARTED) ${ }^{16}$ & 3 & 780 & $\begin{array}{l}\text { High-volume metastatic and } \\
\text { hormone-sensitive } \mathrm{PCa}\end{array}$ & Randomized, open-label \\
\hline NCT00I047I5 (GETUG-AFUI5)15 & 3 & 385 & Metastatic hormone-sensitive PCa & Open-label \\
\hline NCT0092446928 & 2 & 58 & $\begin{array}{l}\text { Neoadjuvant treatment, localized } \\
\text { hormone-sensitive PCa }\end{array}$ & $\begin{array}{l}\text { Randomized, open-label, } \\
\text { parallel-group }\end{array}$ \\
\hline NCT00002855 29 & 3 & 286 & $\mathrm{mPCa}$ or unresectable $\mathrm{PCa}$ & Randomized, open-label \\
\hline NCRN322 (TERRAIN) ${ }^{37}$ & 2 & 375 & $\mathrm{mPCa}$ & Randomized, double-blind \\
\hline
\end{tabular}

Abbreviations: ADT, androgen deprivation therapy; mPCa, metastatic PCa; PCa, prostate cancer.

debate, and research is ongoing to optimize ADT regimens (Tables 1-3). ${ }^{2}$ Studies have tested androgen blockade using different agents alone or in combination, and whether adding chemotherapy to backbone ADT before transition to CRPC can improve the overall survival (OS) for patients with $\mathrm{mPCa}$ (Table 1). ${ }^{15,16}$

\section{Intense androgen blockade for hormone-sensitive $\mathrm{mPCa}$}

The European Organization for Research and Treatment of Cancer (EORTC) conducted two Phase III studies using intense androgen blockade in $\mathrm{mPCa}$, with apparently conflicting results. ${ }^{17-20}$ The EORTC GU Group Trial 30843 compared maximal androgen blockade using a luteinizing hormone-releasing hormone (LHRH) agonist plus cyproterone acetate versus standard LHRH monotherapy or bilateral orchiectomy. ${ }^{19,20}$ Investigators reported no significant difference between survival times, response rates or times to progression in all three treatment groups. ${ }^{19}$ In contrast, the EORTC Phase III trial 30853 found that an intensive androgen-blocking regimen using LHRH plus flutamide was associated with significantly improved outcomes compared with bilateral orchiectomy. ${ }^{17,18}$ Time to death due to malignant disease, time to first progression, progression-free survival (PFS) and duration of survival were significantly better in patients receiving intense androgen blockade compared with bilateral orchiectomy $(P=0.008, P=0.009$, $P=0.02$, and $P=0.04$, respectively). ${ }^{17}$ The HR for overall

Table 2 Summary of ongoing Phase II clinical studies with ADT as backbone therapy in PCa

\begin{tabular}{|c|c|c|c|c|}
\hline $\begin{array}{l}\text { Study } \\
\text { no/name }\end{array}$ & No of Pts & Design & Treatments & Pts, end points/planned completion \\
\hline NCTOI 786265 & 200 & $\begin{array}{l}\text { Randomized, open- } \\
\text { label, crossover }\end{array}$ & $\begin{array}{l}\mathrm{LHRH} \text { alone vs } \mathrm{LHRH}+ \\
\text { abiraterone acetate }+ \text { prednisone }\end{array}$ & $\begin{array}{l}\text { Pts with PSA progression after prostatectomy } \\
\text { and/or radiotherapy. Pts with PSA progression } \\
\text { will enter crossover phase } \\
\text { Primary: PSA-free survival (PSA }<0.1 \mathrm{ng} / \mathrm{mL} \text { ) } \\
\text { at } 12 \text { months after treatment (February } 2017 \text { ) }\end{array}$ \\
\hline NCT0I946I65 & 69 & Randomized, open-label & $\begin{array}{l}\text { Abiraterone acetate }+ \text { LHRH } \\
\text { agonist vs abiraterone acetate }+ \\
\text { LHRH agonist and enzalutamide } \\
\text { for } 6 \text { months }\end{array}$ & $\begin{array}{l}\text { Pts with PCa at high risk of recurrence } \\
\text { Difference in pathological stage } \leq \text { pT2 at } \\
\text { prostatectomy over } 6 \text { months. Proportion of } \\
\text { Pts with } \leq \text { PT2 (October 202I) }\end{array}$ \\
\hline NCT0I75I45 I & 120 & $\begin{array}{l}\text { Randomized, open- } \\
\text { label, parallel group }\end{array}$ & $\begin{array}{l}\text { Abiraterone acetate only vs } \\
\text { abiraterone acetate }+ \text { degarelix } \\
\text { vs degarelix only }\end{array}$ & $\begin{array}{l}\text { Pts with PCa with a rising PSA or a rising PSA } \\
\text { and nodal disease following definitive radical } \\
\text { prostatectomy } \\
\text { Primary: PFS (undetectable PSA), soft tissue } \\
\text { complete response. Secondary: PSA response } \\
\text { rate, percentage with a non-castrate level of } \\
\text { testosterone, overall QoL, non-hematological } \\
\text { adverse events, LH recovery rates (October 2016) }\end{array}$ \\
\hline $\begin{array}{l}\text { NCT02077634 } \\
\text { (SPARE) }\end{array}$ & 70 (recruiting) & Randomized, open-label & $\begin{array}{l}\text { Abiraterone acetate }+ \\
\text { prednisone } \pm \text { LHRH therapy }\end{array}$ & $\begin{array}{l}\text { Pts with progressive chemotherapy-naïve CRPC } \\
\text { (October 2016) }\end{array}$ \\
\hline $\begin{array}{l}\text { NCT02640534 } \\
\text { (IMPROVE) }\end{array}$ & $\begin{array}{l}\text { I68 (to start } \\
\text { recruiting, } \\
\text { June } 2016 \text { ) }\end{array}$ & $\begin{array}{l}\text { Randomized, open-label, } \\
\text { active comparator, } \\
\text { parallel assignment }\end{array}$ & Enzalutamide \pm metformin & Pts with CRPC, which is progressing on ADT \\
\hline
\end{tabular}

Abbreviations: ADT, androgen deprivation therapy; CRPC, castration-resistant PCa; LH, luteinizing hormone; LHRH, LH-releasing hormone; PCa, prostate cancer; PFS, progression-free survival; PSA, prostate-specific antigen; Pts, patients; QoL, quality of life. 


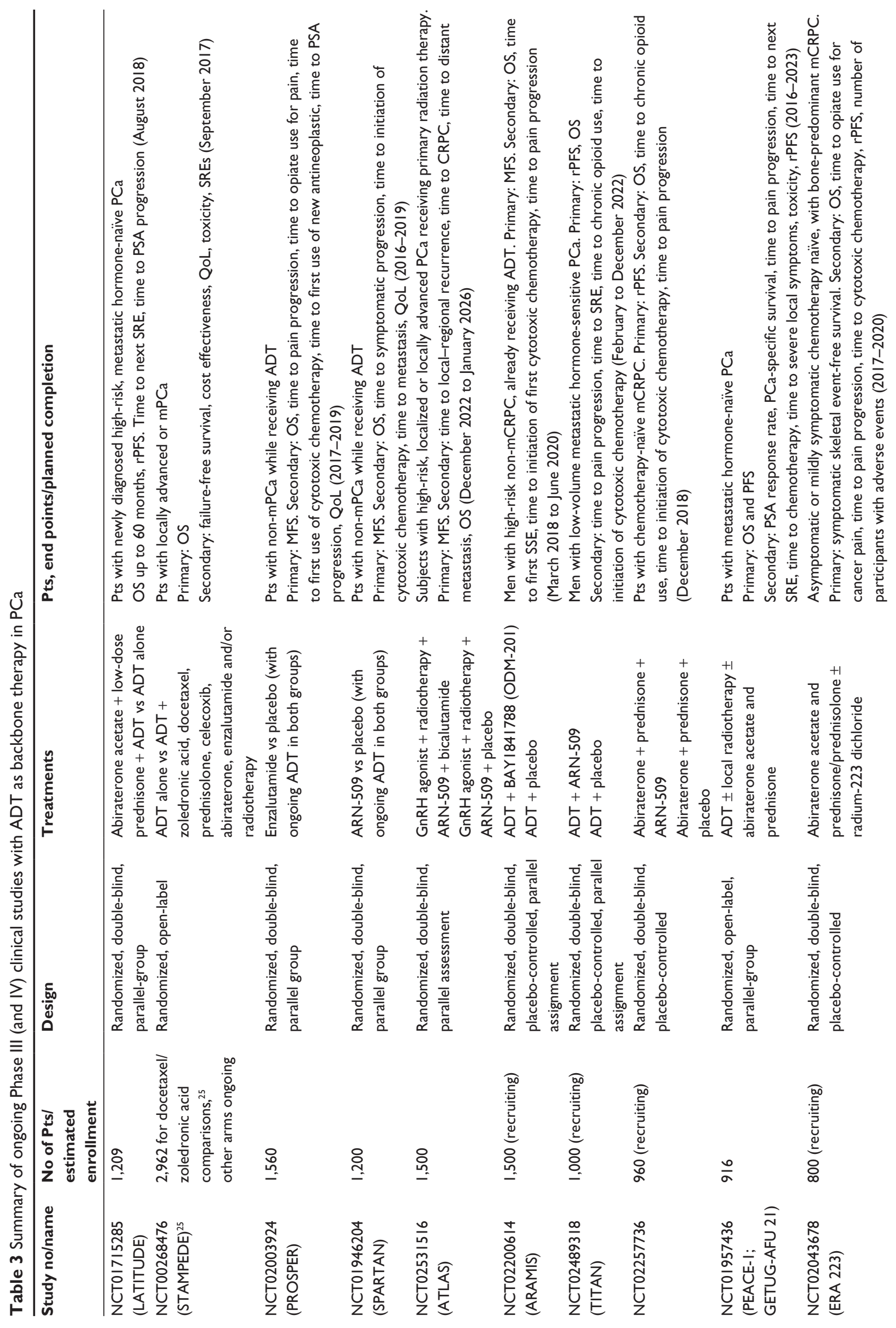



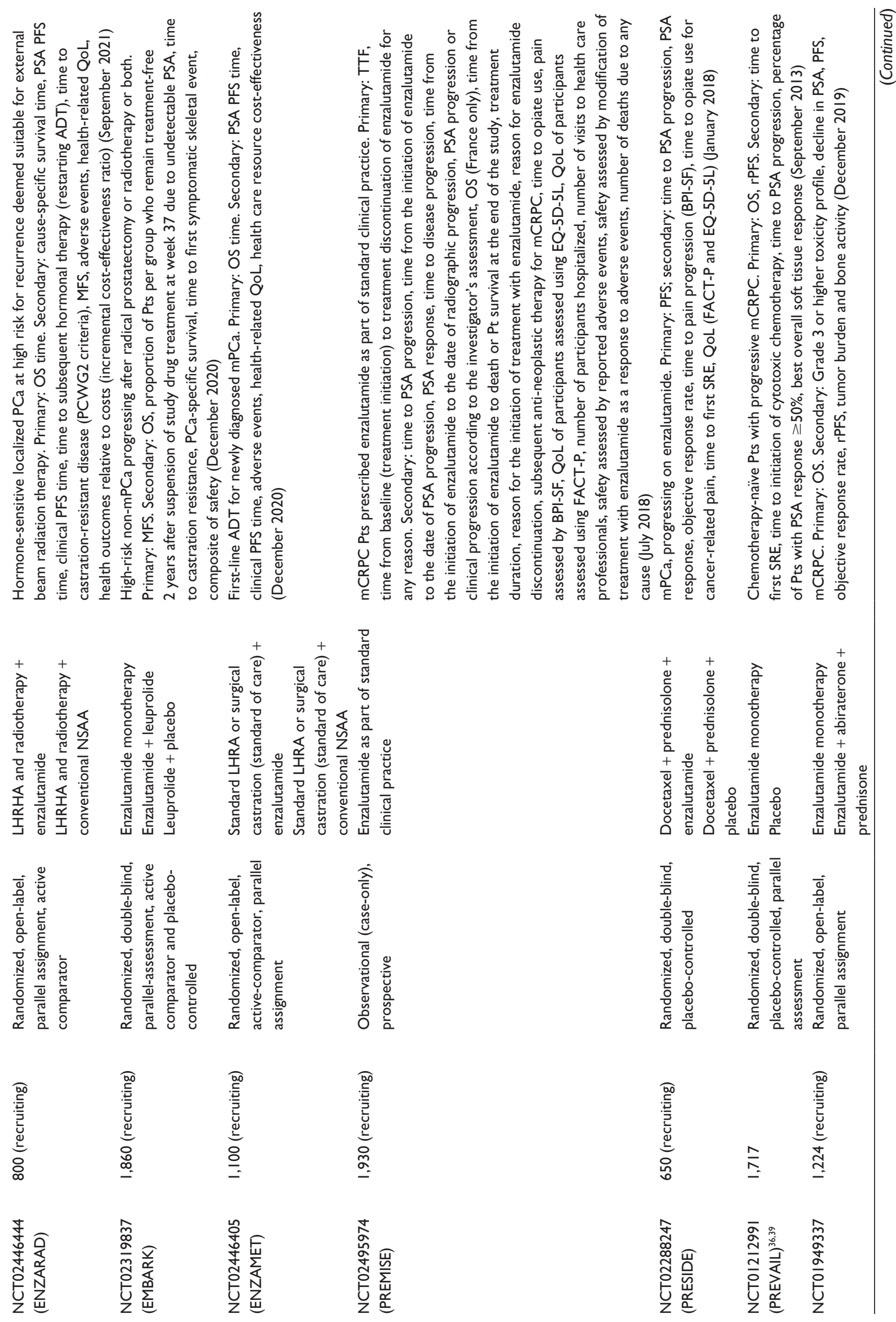


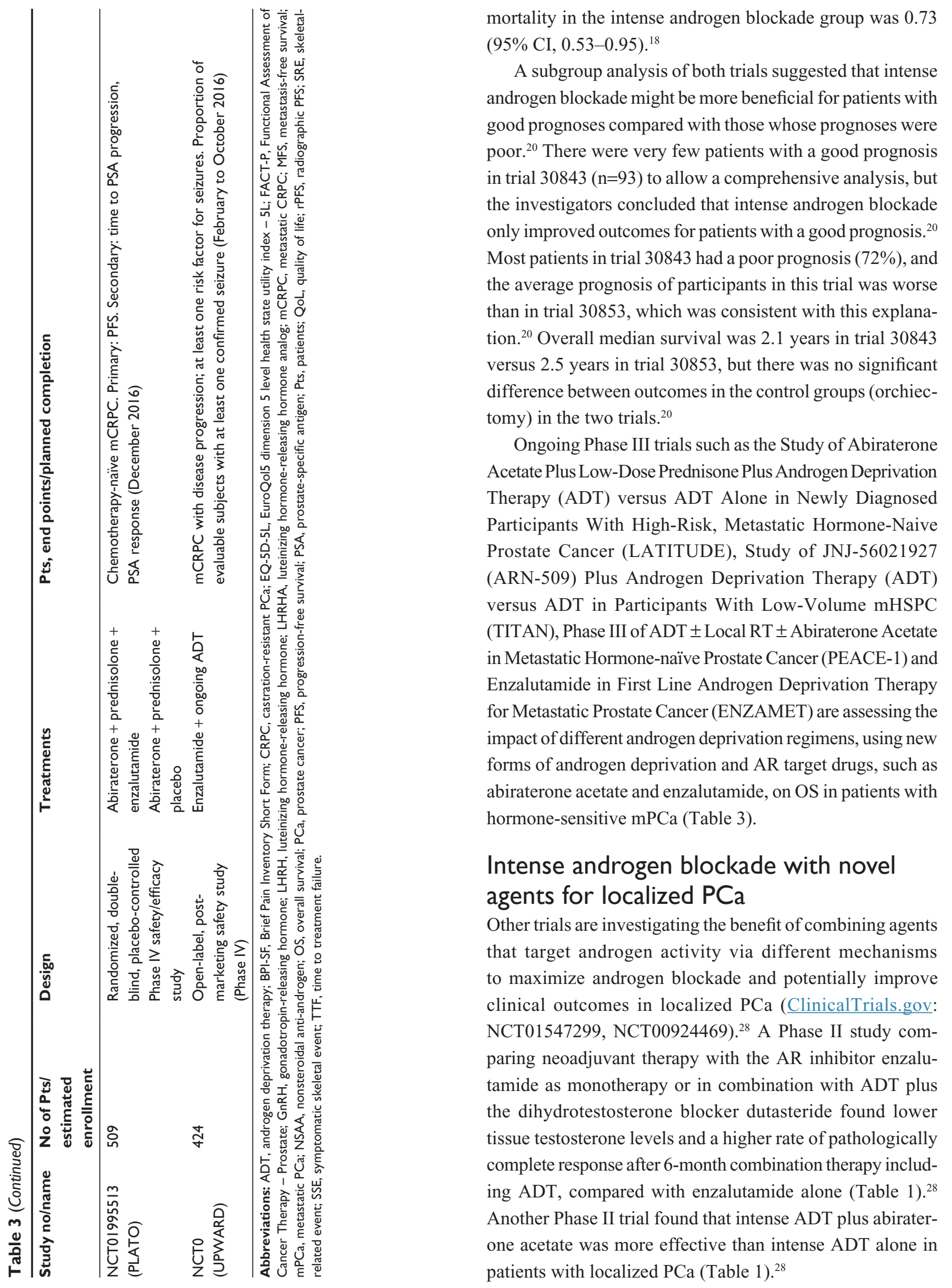


Two Phase III trials are also investigating intense androgen blockade for patients with hormone-sensitive nonmPCa: Enzalutamide in Androgen Deprivation Therapy With Radiation Therapy for High Risk, Clinically Localized, Prostate Cancer (ENZARAD; ClinicalTrials.gov: NCT02446444) and Safety and Efficacy Study of Enzalutamide Plus Leuprolide in Patients With Nonmetastatic Prostate Cancer (EMBARK; NCT02319837).

\section{Chemotherapy in metastatic hormone- sensitive $\mathrm{PCa}$}

An increasing body of evidence suggests that adding chemotherapy to ADT may improve survival in patients with hormone-sensitive $\mathrm{mPCa}$. Studies have generated apparently conflicting results, and these trials, such as the intensive androgen blockade studies described earlier, have also identified subsets of patients who seem most likely to benefit from this treatment approach.

\section{The CHAARTED trial}

The Eastern Cooperative Oncology Group ChemoHormonal Therapy versus Androgen Ablation Randomized Trial for Extensive Disease in Prostate Cancer (ECOGCHAARTED) demonstrated a significant survival benefit for patients who received six cycles of docetaxel at the start of ADT compared with ADT alone (Figure 2).${ }^{16}$ A significant OS survival benefit was seen in patients with high-volume disease (defined as having visceral metastases or $\geq 4$ bone lesions, including at least one outside the vertebrae and pelvis): median OS was 49.2 months versus 32.2 months, respectively, for combined treatment or ADT monotherapy; HR for death, $0.60 ; 95 \% \mathrm{CI}, 0.45-0.81 ; P<0.001 .{ }^{17}$ It is interesting that there was such a strong survival advantage for adding docetaxel to ADT in early phase mPCa, even though 147 of the 287 patients who progressed to CRPC in the ADT-only group subsequently received docetaxel. ${ }^{16}$ The frequency of Grade 3 or higher adverse events in the combined therapy group was comparable with frequencies reported in the docetaxel summary of product characteristics. ${ }^{16,21}$

\section{The GETUG-AFU I 5 trial}

In contrast, investigators on the smaller androgen deprivation therapy alone or with docetaxel in non-castrate $\mathrm{mPCa}$ (GETUG-AFU 15) trial concluded that docetaxel should not be used in the first-line treatment regimens for patients with hormone-sensitive mPCa. ${ }^{15,22}$ PFS was significantly longer in the ADT-plus-docetaxel group, versus ADT alone: 22.9 months versus 12.9 months; HR, $0.72 ; P=0.005$ (biological PFS; clinical PFS was also significantly different), but there was no significant OS advantage for combination therapy (Table 1). ${ }^{15,22}$ Common toxic effects in the ADT plus docetaxel group included neutropenia ( $50 \%$ vs $3 \%$ on ADT monotherapy), anemia ( $72 \%$ vs $22 \%$ on ADT monotherapy), sensory neuropathy ( $29 \%$ vs $4 \%$ on ADT monotherapy) and fatigue ( $74 \%$ vs $20 \%$ on ADT monotherapy). ${ }^{15}$ Mean quality of life scores were also significantly poorer

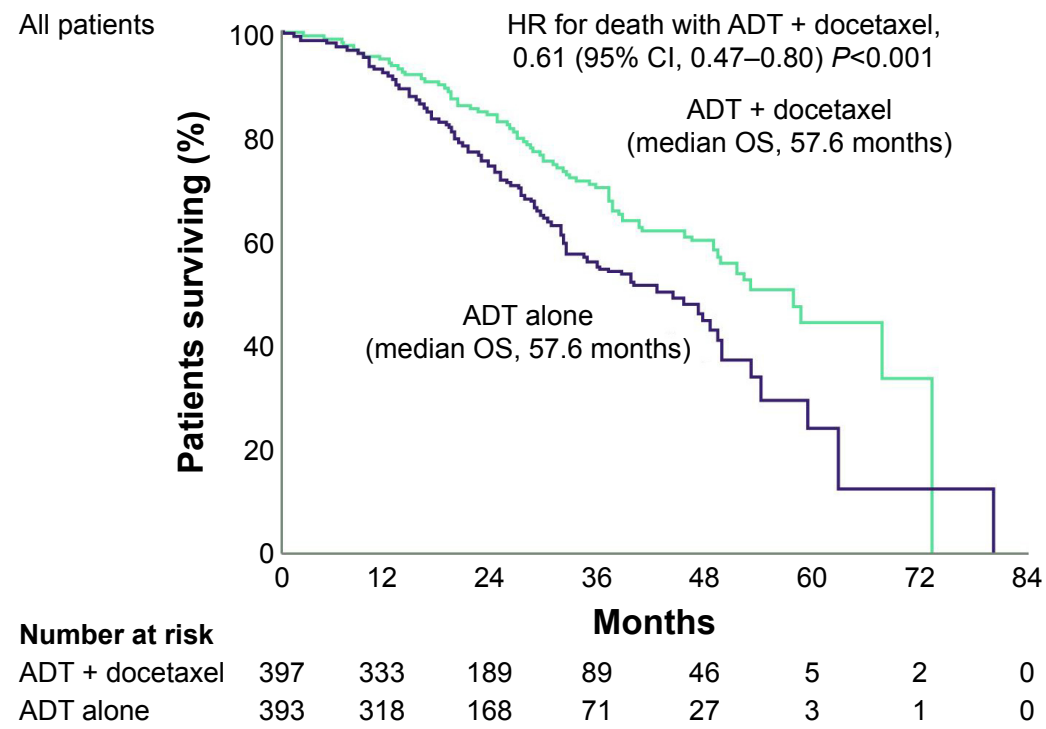

Figure 2 Kaplan-Meier estimates of OS following six cycles of docetaxel at the start of ADT versus ADT alone in the CHAARTED study. Notes: The median duration of follow-up was 28.9 months among all patients. From N Engl J Med. Sweeney CJ, Chen YH, Carducci M, et al. Chemohormonal therapy in metastatic hormone-sensitive prostate cancer. 373(8):737-746. Copyright (C) 2015 Massachusetts Medical Society. Reprinted with permission from Massachusetts Medical Society. ${ }^{16}$ Abbreviations: ADT, androgen deprivation therapy; CHAARTED, Androgen Ablation Therapy with or without Chemotherapy in Treating Patients with Metastatic Prostate Cancer; HR, hazard ratio; OS, overall survival. 
Table 4 Survival outcomes in STAMPEDE trial

\begin{tabular}{|c|c|c|c|c|}
\hline Results & $\begin{array}{l}\text { ADT monotherapy } \\
\text { (standard of care) }\end{array}$ & ADT + docetaxel & ADT + zoledronic acid & $\begin{array}{l}\text { ADT + docetaxel + } \\
\text { zoledronic acid }\end{array}$ \\
\hline Number of patients & $\mathrm{I}, 184$ & 592 & 593 & 593 \\
\hline Number of deaths & 415 & 175 & 201 & 187 \\
\hline OS, HR (95\% Cl) & I & $0.78(0.66,0.93) ; P=0.003$ & $0.94(0.79, \mathrm{I} . \mathrm{I} \mathrm{I}) ; P=0.437$ & $0.82(0.69,0.97) ; P=0.02$ \\
\hline 5-year survival & $55.00 \%$ & $63.00 \%$ & $57.00 \%$ & $60.00 \%$ \\
\hline Failure-free survival, HR & I & $0.62(0.54,0.70)$ & $0.93(0.82,1.05) ; P=0.26$ & $0.62(0.54,0.7 \mathrm{I})$ \\
\hline$(95 \% \mathrm{Cl})$ & & $P<0.0000000001$ & & $P<0.0000000001$ \\
\hline 5-year failure-free survival & $28.00 \%$ & $38.00 \%$ & $31.00 \%$ & $34.00 \%$ \\
\hline
\end{tabular}

Note: Copyright (C) James et al. Adapted from James ND, Sydes MR, Clarke NW, et al; STAMPEDE Investigators. Addition of docetaxel, zoledronic acid, or both to firstline long-term hormone therapy in prostate cancer (STAMPEDE): survival results from an adaptive, multiarm, multistage, platform randomised controlled trial. Lancet. 2016;387(10024): I163-1177.26

Abbreviations: HR, hazard ratio; OS, overall survival.

on combined therapy compared with ADT alone, at both 3- and 6-month follow-up. ${ }^{15}$

These contrasting results have stimulated debate on the value of adding docetaxel to ADT in hormone-sensitive $\mathrm{mPCa}$, and the GETUG-AFU 15 investigators performed a subset analysis, at a mean follow-up of 82.9 months, to assess whether the different outcomes were due to different case mixes in their patient populations. ${ }^{16,22}$ This new analysis found no significant difference in OS between groups receiving $\mathrm{ADT}$ plus docetaxel, or $\mathrm{ADT}$ alone, neither for the whole study population nor for the subgroup of high-volume disease (using the same definitions as the CHAARTED study), although the authors noted that their subsets were underpowered for this retrospective analysis. ${ }^{22}$

\section{The STAMPEDE trial}

The ongoing Systemic Therapy in Advancing or Metastatic Prostate cancer: Evaluation of Drug Efficacy (STAMPEDE) trial is already generating clear evidence on whether to add docetaxel - or other agents - to ADT in early/hormone-naïve PCa. ${ }^{23,24}$ STAMPEDE is comparing ADT monotherapy versus ADT plus chemotherapy, anti-androgen treatment and/or radiotherapy, and has recruited more than 7,000 patients to date (Table 3). ${ }^{23,25,26}$ Results are now available for 2,962 patients randomized to four arms (control/ADT monotherapy, ADT plus six cycles of $75 \mathrm{mg} / \mathrm{m}^{2}$ docetaxel [with $10 \mathrm{mg}$ prednisolone], ADT plus zoledronic acid, or ADT plus docetaxel and zoledronic acid). ${ }^{26,27}$ Adding docetaxel (but not zoledronic acid) to ADT significantly improved OS, with a 10-month extension in median survival from 71 months on ADT alone to 81 months on ADT plus docetaxel (Table 4). ${ }^{26}$ There was no benefit for zoledronic acid on either survival or skeletalrelated events, despite good compliance with therapy. ${ }^{26}$

\section{Conclusion from STAMPEDE and CHAARTED trials for patients with high-risk $\mathrm{PCa}$}

The result of STAMPEDE is consistent with the findings of the CHAARTED study, but, interestingly, STAMPEDE data suggest that docetaxel may be of benefit in both metastatic and non-mPCa. ${ }^{16,26}$ The investigators reported that estimated treatment effects of docetaxel in both PCa-specific survival and failure-free survival were comparable in both patient groups, although the relatively low population size and smaller number of deaths (compared with men who presented with metastatic disease) meant that the non-metastatic subgroup was underpowered to demonstrate improved survival. ${ }^{26}$ STAMPEDE will generate long-term data on these four arms. ${ }^{26}$ The authors concluded that "Standard of care should be updated to include docetaxel chemotherapy in suitable patients with metastatic disease, and docetaxel may be considered for men with high-risk non-metastatic prostate cancer with or without radiotherapy."26

Future STAMPEDE publications will also report on similar comparisons for celecoxib, abiraterone, combination therapy using enzalutamide plus abiraterone and prostate radiotherapy. ${ }^{26}$

It is interesting to note that an earlier study of 589 men with advanced $\mathrm{PCa}$, of whom $46 \%$ had locally advanced $\mathrm{T} 3$ or T4 disease and $52 \%$ had metastatic disease, also found a similar benefit of intensive androgen blockade in both groups ${ }^{26}$ The authors reported a nonsignificant improvement in survival when they added flutamide to LHRH therapy in patients who were hormone naïve. ${ }^{27}$

\section{Optimizing therapy in CRPC}

A number of clinical studies have investigated the benefit of combining ADT with various other agents, including enzalutamide, abiraterone acetate, chemotherapy, radium-223 and novel agents, following the development of CRPC (Table 1 and Figure 3). ${ }^{29-37}$ Figure 3 shows the findings of Phase III trial in patients with previously untreated $\mathrm{mPCa}$ that tested hypothesis that three 8-week cycles of ketoconazole and doxorubicin alternating with vinblastine and estramustine, given in addition to standard androgen deprivation, would delay the appearance of castration-resistant disease. 
A

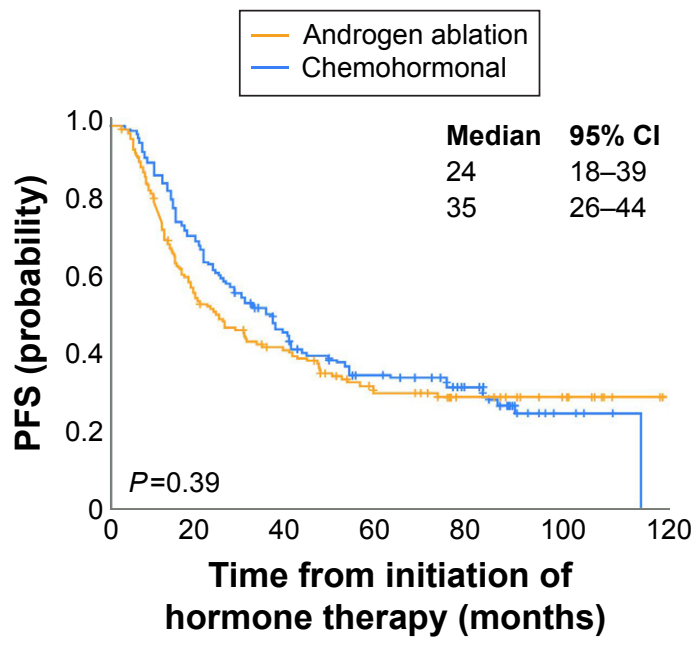

Number of patients at risk

Androgen ablation $77 \quad 54 \quad 33 \quad 20 \quad 11$

B

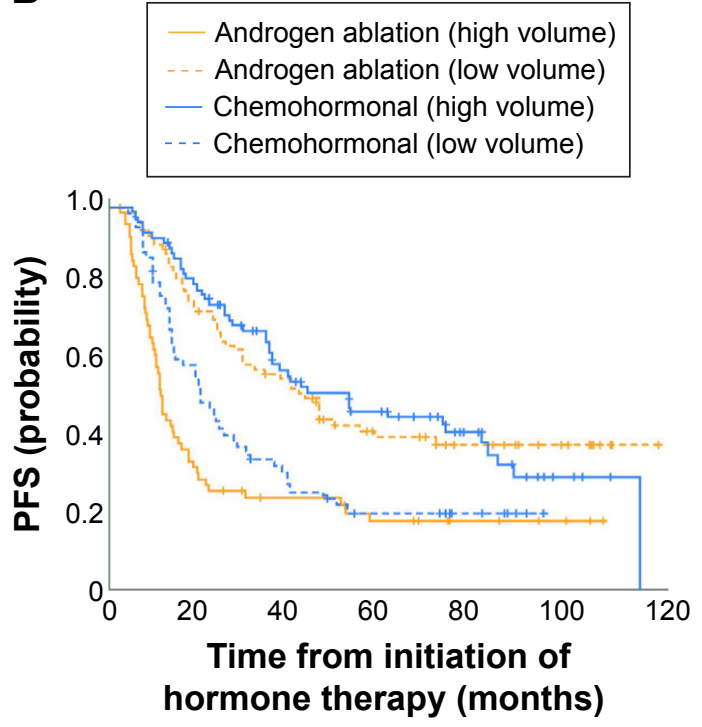

Figure 3 TPP with standard androgen ablation therapy versus three cycles of systemic chemotherapy in a Phase III trial in advanced PCa.

Notes: (A) TTP by assigned treatment. (B) TTP by treatment, stratified by disease volume at entry. Reprinted with permission. (C) 2008 American Society of Clinical Oncology. All rights reserved. Millikan RE, Wen S, Pagliaro LC, et al. Phase III trial of androgen ablation with or without three cycles of systemic chemotherapy for advanced prostate cancer. J Clin Oncol. 2008;26(36):5936-5942. ${ }^{29}$

Abbreviations: PCa, prostate cancer; PFS, progression-free survival; TTP, time to progression.

\section{ADT during radium-223}

Radium-223 has been associated with significantly improved survival, versus placebo: in an interim analysis $(\mathrm{n}=809)$ of a Phase III trial of men with metastatic CRPC (mCRPC), the median OS was 14.0 months versus 11.2 months on placebo; HR 0.70 (95\% CI, 0.58-0.83); $P=0.002 .{ }^{38}$ This study applied a pragmatic approach, allowing clinicians to prescribe best standard of care, at their own discretion, throughout the study, meaning that the results may be more applicable to clinical practice than other trials. ${ }^{38}$ It is unclear how many of these patients received ADT during the study, although they were required to continue their maintenance treatment. ${ }^{38}$

\section{Abiraterone acetate}

Abiraterone acetate has demonstrated the efficacy in Phase III trials when added to ADT for men with progressive mCRPC, both before and after receiving chemotherapy. ${ }^{33,35}$

The COU-AA-301 study revealed a significant survival benefit of abiraterone acetate in 1,195 men with mCRPC, which had progressed following docetaxel. ${ }^{33}$ Median OS was 15.8 months in the abiraterone acetate plus prednisone group versus 11.2 months on prednisone plus placebo, after a median follow-up of 20.2 months (HR, 0.74; 95\% CI, 0.64-0.86; $P<0.0001) .{ }^{34}$ This OS benefit was consistent across subgroups (according to prespecified analyses) ${ }^{33}$ Median radiographic PFS (rPFS) was 5.6 months and 3.6 months on abiraterone acetate and placebo, respectively (HR, 0.66; 95\% CI, 0.58-0.76; $P<0.0001){ }^{33}$

In the COU-AA-302 study, abiraterone acetate (with prednisone) was linked with significantly improved survival versus placebo (plus prednisone) in 1,088 patients with mCRPC who were asymptomatic or minimally symptomatic and had received no prior chemotherapy. ${ }^{35}$ There were 147 deaths in the abiraterone-treated group $(\mathrm{n}=546 ; 27 \%)$ and 186 deaths in the prednisone-only group $(\mathrm{n}=542 ; 34 \%)$, at a median follow-up of 22.2 months. ${ }^{35} \mathrm{HRs}$ for OS and rPFS were $0.75(95 \% \mathrm{CI}, 0.61-0.93 ; P=0.01)$ and $0.53(95 \% \mathrm{CI}$, $0.45-0.62 ; P<0.001)$, respectively. ${ }^{35}$ Abiraterone showed a consistent benefit across subgroups. ${ }^{35}$

\section{Enzalutamide}

Adding the oral AR inhibitor enzalutamide to ongoing ADT also significantly improves survival in CRPC, according to two large Phase III studies. ${ }^{34,39}$ Both trials (Safety and Efficacy Study of MDV3100 in Patients With Castration-Resistant Prostate Cancer Who Have Been Previously Treated With Docetaxel-based Chemotherapy [AFFIRM] and Safety and Efficacy Study of Oral MDV3100 in ChemotherapyNaive Patients With Progressive Metastatic Prostate Cancer [PREVAIL]) included patients with progressive mCRPC, and serum testosterone levels of $1.7 \mathrm{nmol} / \mathrm{L}(50 \mathrm{ng} / \mathrm{dL})$ or less, maintained with regular hormonal ADT (unless they 
had previously undergone orchiectomy). ${ }^{34,39}$ The AFFIRM study investigators recruited patients who had previously received docetaxel, while the PREVAIL trial included patients who had not received chemotherapy. ${ }^{34,39}$ Both studies were stopped after interim analyses that revealed significant survival benefits of treatment. ${ }^{34,39}$

AFFIRM included 1,199 patients who were randomized to receive either enzalutamide $(n=800)$ or placebo $(n=399)$ with backbone ADT and bisphosphonate therapy. ${ }^{34}$ Median OS was 18.4 months in the enzalutamide group versus 13.6 months on placebo (HR, 0.63 ; 95\% CI, 0.53-0.75; $P<0.001) .{ }^{34}$ All secondary end points also showed significant improvements on enzalutamide, including time to PSA progression (HR, $0.25 ; 95 \% \mathrm{CI}, 0.20-0.30 ; P<0.001$ ) and rPFS (HR, 0.40; 95\% CI, 0.45-0.47; $P<0.001$ ). ${ }^{34}$ Adverse event rates were similar in the enzalutamide and placebo groups, even though the observation period for enzalutamide was more than double that of the placebo group. ${ }^{34}$

Chemotherapy-naïve patients entering the PREVAIL study were also randomized to receive either enzalutamide ( $\mathrm{n}=872)$ or placebo $(\mathrm{n}=845)$ in combination with ongoing ADT. ${ }^{39}$ Enzalutamide-treated men had better OS than controls, with an estimated median survival time of 32.4 months versus 30.2 months on placebo (HR, $0.71 ; 95 \%$ CI, $0.60-0.84 ; P<0.001){ }^{36,39}$ The HR for rPFS was $0.19(95 \%$ CI, $0.15-0.23 ; P<0.001) .{ }^{39}$ Several ongoing Phase III trials are comparing different therapeutic approaches to mCRPC, as summarized in Table 3.

\section{Non-mCRPC}

Optimizing management of non-mCRPC could dramatically improve survival for many thousands of men with $\mathrm{PCa}$. A recent large-scale data analysis reported a total PCa prevalence of 2,219,280 in the USA in 2009, with an annual all-cause mortality of $168,290 .{ }^{40}$ The authors estimated an mCRPC incidence of only 36,100 (1.6\%), but this group contributed 34,525 annual deaths $(20.5 \%$ of total deaths in men with PCa). ${ }^{40}$ Optimal treatment at the non-mCPRC stage could delay progression to metastatic disease, in which this model predicted to be $34 \%$ each year. ${ }^{40}$ Annual all-cause mortality in mCPRC was $56 \%$, and $86 \%$ of mCPRC had progressed from non-mCPRC..$^{40}$ Reducing annual progression from non-mCPRC to mCPRC by $11.5 \%$ could prevent 3,694 deaths per year, according to this model. ${ }^{40}$

Results of four large-scale Phase III trials with a total planned population over 5,800 patients with non-mCRPC are due to become available over the next $1-10$ years (Table 3 ). Tables 2 and 3 summarize some key ongoing Phase II and III randomized clinical trials investigating the efficacy and safety of abiraterone, enzalutamide or ARN-509, with or without $\mathrm{ADT}$ and other treatments, in both metastatic and non-mPCa.

\section{Future developments}

Accumulating evidence for the benefits of combining ADT with chemotherapy, at least using docetaxel, may encourage many clinicians to adopt this approach. This could substantially increase OS in a large population of men with PCa. Enzalutamide or abiraterone acetate may potentially be used before CRPC develops, either as an alternative to ADT or in combination with ADT (Tables 2 and 3).

The optimal approach to treating patients with nonmCRPC remains an open question. Limited data availability and the small number of ongoing studies (notably PROSPER, SPARTAN and ARAMIS; Table 3) means these decisions may remain uncertain, although there are encouraging preliminary results from the ongoing STAMPEDE trial. There is a clear need for more research in this area, to allow clinicians to make informed decisions for this group of patients, which could transform outcomes in PCa. Increased numbers of reliable biomarkers and genetic profiling may help to determine which patients to treat, with which type of treatment and by when. Personalized/individualized medicine in PCa will become a reality as more treatment options/combinations that include ADT become available which are supported by clinical data.

\section{Conclusion}

Clinical studies to date have shown the benefit of maintaining ADT as backbone therapy in combination with other treatment modalities in $\mathrm{mPCa}$, but data are limited. Further studies are needed to determine the most appropriate use of backbone ADT therapy in CRPC. The safety and tolerability of chemotherapy regimens are not markedly changed by continuing $\mathrm{ADT}$ as backbone treatment. The key question is whether continuing ADT following the development of CRPC, irrespective of the additional treatments given, prolongs survival for patients with an acceptable level of side effects.

\section{Acknowledgments}

Editorial assistance was provided by Shari Barber-Bailey and Catherine Amey for Touch Medical Media, funded by Ipsen.

\section{Disclosure}

ASM is the advisor and speaker for Bayer, Astellas, Janssen, TEVA, Novartis, BMS, Ipsen, Medac, Pfizer, GSK, Takeda, Astra Zeneca and Merck. CAvK is the advisor and/or speaker for Janssen, TEVA, Novartis, BMS, Astellas, Galil Medical, 
Bayer and Sennewald. AA is the lecturer for Astellas, Olympus, Janssen, Sanofi and Ipsen. The authors report no other conflicts of interest in this work.

\section{References}

1. Huggins C, Stevens RE, Hodges CV. Studies on prostatic cancer, II: the effect of castration on advance prostatic carcinoma of the prostate gland. Arch Surg. 1941;43:209-228.

2. Schulman CC, Irani J, Morote J. Deprivation therapy in prostate cancer: a European Expert Panel Review. Eur Urol Suppl. 2010;9: 675-691.

3. Mottet N, Bellmunt N, Briers E, et al. European Association of Urology Guidelines on Prostate Cancer, 2015. Available from: http://uroweb. org/wp-content/uploads/EAU-Guidelines-Prostate-Cancer-2015-v2. pdf. Accessed August 17, 2015.

4. National Comprehensive Cancer Network. 2015 NCCN Guideline Prostate Cancer. Available from: https://www.nccn.org/patients/ guidelines/prostate/. Accessed November 4, 2015.

5. Sternberg CN, Baskin-Bey ES, Watson M, Worsfold A, Rider A, Tombal B. Treatment patterns and characteristics of European patients with castration-resistant prostate cancer. BMC Urol. 2013;13:58.

6. Merseburger AS, Hammerer P, Rozet F, et al. Androgen deprivation therapy in castrate-resistant prostate cancer: how important is $\mathrm{GnRH}$ agonist backbone therapy? World J Urol. 2015;33(8):1079-1085.

7. Cookson MS, Roth BJ, Dahm P, et al. Castration-resistant prostate cancer: AUA guideline. J Urol. 2013;190(2):429-438.

8. Heidenreich A, Bastian PJ, Bellmunt J, et al; European Association of Urology. EAU guidelines on prostate cancer. Part II: treatment of advanced, relapsing, and castration-resistant prostate cancer. Eur Urol. 2014;65(2):467-479

9. Rodriguez-Vida A, Galazi M, Rudman S, Chowdhury S, Sternberg CN. Enzalutamide for the treatment of metastatic castration-resistant prostate cancer. Drug Des Devel Ther. 2015;9:3325-3339.

10. Oefelein MG, Feng A, Scolieri MJ, Ricchiutti D, Resnick MI. Reassessment of the definition of castrate levels of testosterone: implications for clinical decision making. Urology. 2000;56(6):1021-1024.

11. Morote J, Orsola A, Planas J, et al. Redefining clinically significant castration levels in patients with prostate cancer receiving continuous androgen deprivation therapy. J Urol. 2007;178(4 pt 1):1290-1295.

12. Lebret $\mathrm{T}$, Rouanne $\mathrm{M}$, Hublarov $\mathrm{O}$, et al. Efficacy of triptorelin pamoate $11.25 \mathrm{mg}$ administered subcutaneously for achieving medical castration levels of testosterone in patients with locally advanced or metastatic prostate cancer. Ther Adv Urol. 2015;7(3):125-134.

13. Klotz L, O'Callaghan C, Ding K, et al. Nadir testosterone within first year of androgen-deprivation therapy (ADT) predicts for time to castration-resistant progression: a secondary analysis of the PR-7 trial of intermittent versus continuous ADT. J Clin Oncol. 2015;33(10): $1151-1156$.

14. Keto CJ, Aronson WJ, Terris MK, et al. Detectable prostate-specific antigen Nadir during androgen-deprivation therapy predicts adverse prostate cancer-specific outcomes: results from the SEARCH database. Eur Urol. 2014;65(3):620-627.

15. Gravis G, Fizazi K, Joly F, et al. Androgen-deprivation therapy alone or with docetaxel in non-castrate metastatic prostate cancer (GETUGAFU 15): a randomised, open-label, phase 3 trial. Lancet Oncol. 2013; 14(2):149-158.

16. Sweeney CJ, Chen YH, Carducci M, et al. Chemohormonal therapy in metastatic hormone-sensitive prostate cancer. $N$ Engl J Med. 2015; 373(8):737-746.

17. Denis LJ, Keuppens F, Smith PH, et al. Maximal androgen blockade: final analysis of EORTC phase III trial 30853. EORTC Genito-Urinary Tract Cancer Cooperative Group and the EORTC Data Center. Eur Urol. 1998;33(2):144-151.

18. Denis LJ, Carnelro de Moura JL, Bono A, et al. Goserelin acetate and flutamide versus bilateral orchiectomy: a phase III EORTC trial (30853). EORTC GU Group and EORTC Data Center. Urology. 1993; 42(2):119-129. [discussion 129-130].
19. de Voogt HJ, Studer U, Schröder FH, Klijn JG, de Pauw M, Sylvester R. Maximum androgen blockade using LHRH agonist buserelin in combination with short-term (two weeks) or long-term (continuous) cyproterone acetate is not superior to standard androgen deprivation in the treatment of advanced prostate cancer. Final analysis of EORTC GU Group Trial 30843. European Organization for Research and Treatment of Cancer (EROTC) Genito-Urinary Tract Cancer Cooperative Group. Eur Urol. 1998;33(2):152-158.

20. Sylvester RJ, Denis L, de Voogt H. The importance of prognostic factors in the interpretation of two EORTC metastatic prostate cancer trials. European Organization for Research and Treatment of Cancer (EORTC) Genito-Urinary Tract Cancer Cooperative Group. Eur Urol. 1998;33(2): 134-143.

21. European Medicines Agency. Summary of Product Characteristics Taxotere. Available from: http://www.ema.europa.eu/docs/en_GB/ document_library/EPAR_-_Product_Information/human/000073/ WC500035264.pdf. Accessed April 22, 2016.

22. Gravis G, Boher J-M, Joly F, et al; GETUG. Androgen deprivation therapy (ADT) plus docetaxel (D) versus ADT alone for hormone-naïve metastatic prostate cancer (PCa): long-term analysis of the GETUGAFU 15 phase III trial. J Clin Oncol. 2015;33(suppl 7):abstr140.

23. Stampede Trial. Protocol v13. Available from: http://www. stampedetrial.org/PDF/STAMPEDE_Protocol_v13.0_clean.pdf. Accessed April 22, 2016.

24. James ND, Spears MR, Clarke NW, et al. Survival with newly diagnosed metastatic prostate cancer in the "Docetaxel Era": data from 917 patients in the control arm of the STAMPEDE Trial (MRC PR08, CRUK/06/019). Eur Urol. 2015;67:1028-1038.

25. James ND, Sydes MD, Mason MD. Docetaxel and/or zoledronic acid for hormone-naïve prostate cancer: first overall survival results from STAMPEDE (NCT00268476). J Clin Oncol. 2015; 33(suppl):abstr5001.

26. James ND, Sydes MR, Clarke NW, et al; STAMPEDE Investigators. Addition of docetaxel, zoledronic acid, or both to first-line long-term hormone therapy in prostate cancer (STAMPEDE): survival results from an adaptive, multiarm, multistage, platform randomised controlled trial. Lancet. 2016;387(10024):1163-1177.

27. Tyrrell CJ, Altwein JE, Klippel F, et al. Comparison of an LH-RH analogue (Goeserelin acetate, 'Zoladex') with combined androgen blockade in advanced prostate cancer: final survival results of an international multicentre randomized-trial. International Prostate Cancer Study Group. Eur Urol. 2000;37(2):205-211.

28. Taplin ME, Montgomery B, Logothetis CJ, et al. Intense androgendeprivation therapy with abiraterone acetate plus leuprolide acetate in patients with localized high-risk prostate cancer: results of a randomized phase II neoadjuvant study. J Clin Oncol. 2014;32(33):3705-3715.

29. Millikan RE, Wen S, Pagliaro LC, et al. Phase III trial of androgen ablation with or without three cycles of systemic chemotherapy for advanced prostate cancer. J Clin Oncol. 2008;26(36):5936-5942.

30. de Bono JS, Oudard S, Ozguroglu M, et al; TROPIC Investigators. Prednisone plus cabazitaxel or mitoxantrone for metastatic castrationresistant prostate cancer progressing after docetaxel treatment: a randomised open-label trial. Lancet. 2010;376(9747):1147-1154.

31. Liu G, Kelly WK, Wilding G, Leopold L, Brill K, Somer B. An open-label, multicenter, phase I/II study of single-agent AT-101 in men with castrate-resistant prostate cancer. Clin Cancer Res. 2009;15: 3172-3176.

32. Kantoff PW, Higano CS, Shore ND, et al; IMPACT Study Investigators. Sipuleucel-T immunotherapy for castration-resistant prostate cancer. N Engl J Med. 2010;363(5):411-422.

33. Fizazi K, Scher HI, Molina A, et al; COU-AA-301 Investigators. Abiraterone acetate for treatment of metastatic castration-resistant prostate cancer: final overall survival analysis of the COU-AA-301 randomised, double-blind, placebo-controlled phase 3 study. Lancet Oncol. 2012;13(10):983-992.

34. Scher HI, Fizazi K, Saad F, et al; AFFIRM Investigators. Increased survival with enzalutamide in prostate cancer after chemotherapy. N Engl J Med. 2012;367(13):1187-1197. 
35. Ryan CJ, Smith MR, de Bono JS, et al; COU-AA-302 Investigators. Abiraterone in metastatic prostate cancer without previous chemotherapy. N Engl J Med. 2013;368(2):138-148.

36. Beer TM, Armstrong AJ, Sternberg CN, et al. Enzalutamide in men with chemotherapy-naïve metastatic prostate cancer (mCRPC): results of phase III PREVAIL Study. J Clin Oncol. 2014;32(suppl 4).

37. Chowdhury S, Heidenreich A, Villers A, et al. TERRAIN. J Clin Oncol. 2015;33(suppl):Abstract5049.

38. Parker C, Nilsson S, Heinrich D, et al; ALSYMPCA Investigators. Alpha emitter radium-223 and survival in metastatic prostate cancer. N Engl J Med. 2013;369(3):2130223.
39. Beer TM, Armstrong AJ, Rathkopf DE, et al; PREVAIL Investigators. Enzalutamide in metastatic prostate cancer before chemotherapy. $\mathrm{NEngl}$ J Med. 2014;371(5):424-433.

40. Scher HI, Solo K, Valant J, Todd MB, Mehra M. Prevalence of prostate cancer clinical states and mortality in the United States: estimates using a dynamic progression model. PLoS One. 2015;10(10):e0139440.

\section{Publish your work in this journal}

OncoTargets and Therapy is an international, peer-reviewed, open access journal focusing on the pathological basis of all cancers, potential targets for therapy and treatment protocols employed to improve the management of cancer patients. The journal also focuses on the impact of management programs and new therapeutic agents and protocols on

\section{Dovepress}

patient perspectives such as quality of life, adherence and satisfaction. The manuscript management system is completely online and includes a very quick and fair peer-review system, which is all easy to use. Visit http://www.dovepress.com/testimonials.php to read real quotes from published authors. 